\title{
USAGE OF THE LIFE CYCLE ASSESSMENT METHOD FOR ENVIRONMENTAL IMPACT ASSESSMENT OF WASTEWATER TREATMENT PLANT
}

\author{
${ }^{1}$ Réka CSICSAIOVÁ*, ${ }^{2}$ Štefan STANKO, ${ }^{3}$ Mária DUBCOVÁ \\ ${ }^{1,2,3}$ Department of Sanitary and Environmental Engineering, Faculty of Civil Engineering \\ Slovak University of Technology in Bratislava, Radlinského 11, 81005 Bratislava, Slovakia \\ e-mail: ${ }^{1}$ reka.csicsaiova@stuba.sk, ${ }^{2}$ stefan.stanko@stuba.sk, ${ }^{3}$ maria.dubcova@stuba.sk
}

Received 29 December 2017; accepted 18 June 2018

\begin{abstract}
The implementation of Directive 91/271/ECC concerning Urban Wastewater Treatment, leads to increase in the number of waste water treatment plants in Slovakia.The contribution is aimed at assessing the environmental impacts of the wastewater treatment process within the wastewater treatment plant using life cycle assessment. Life cycle assessment is an optional environmental management tool that focuses on the entire life cycle of a product and uses assessment methods to determinate adverse environmental impacts. The assessment of wastewater treatment plant is focused to the analysis of the individual factors identified by the physical-chemical analysis of wastewater. The correct application of the ISO 14040 standard assigns the accuracy of the analysis results and determines the individual elements of the system. Based on this ISO standard the system boundaries, the functional unit and the subsystems are defined.
\end{abstract}

Keywords: Wastewater, Life cycle assessment analysis, Wastewater treatment plant, Negative environmental impact

\section{Introduction}

WasteWater Treatment Plants (WWTP) are considered as a mechanism for the ecological disposal of wastewater. They cause negative environmental impacts during their operation. Energy consumption of WWTP, use of various chemical agents, air pollution accrues from activation processes are environmental factors that have an influence during the wastewater treating process. The implementation of Directive

\footnotetext{
${ }^{*}$ Corresponding Author
} 
91/271/ECC concerning Urban Wastewater Treatment [1], leads to increase in the number of WWTPs in Slovakia. However, Slovakia has committed to sub-serve the requirements of Directive 2000/60/EC (Framework for the Community action in the field of water policy). Therefore, it is necessary to analyze the activity of WWTPs in order to assess its impact on the environment. Government Regulation 269/2010 [2] laying down requirements for achieving good water status sets limit values for discharged wastewater pollution indicators. They may also disrupt the receiving water's aquatic ecosystem. Currently, to environmental impact assessment is used the mandatory tools Environmental Impact Assessment (EIA) or environmental risk management) [3]. These tools are set in Act no. 24/2006 Coll. on Environmental Impact Assessment and on Amendments to Certain Acts. There are several optional assessment tools, including Eco-Management and Audit Scheme (EMAS), Green Public Procurement (GPP) or Life Cycle Assessment (LCA), that serve to evaluation of environmental impacts.

LCA is a universal tool of product environmental impact assessment due to its entire life cycle [4]. It is one of the optional tools of environmental management and can be used in almost every area of the economy. The main idea behind the usage of the LCA study is to limit or even eliminate the adverse environmental impacts arising from the increase in product quality [5].

\section{Life cycle assessment}

Life cycle assessment is an analytical method for assessing the environmental impacts of processes and products. It evaluates their environmental impacts with respect to the life cycle [6]. The impact of products or processes on the environment is considered as an open chain [7]. LCA ascertains the environmental impacts of products or systems from cradle to grave [8]. Fig. 1 represents the scheme and the phases of LCA.

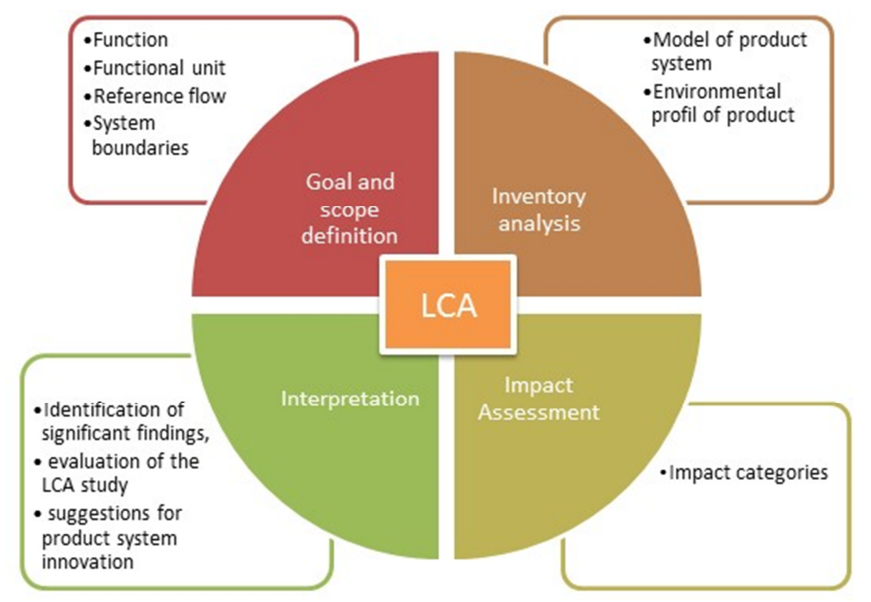

Fig. 1. Life Cycle Assessment phases, (on the basis of [4]) 
The Society of Environmental Toxicology And Chemistry (SETAC) guideline for life cycle assessment is the basis for the creation of international standards for LCA. The methodology of LCA is standardized within EU by ISO Standards 14000 and in Slovakia are most commonly used ISO 14040 and ISO 14044. According to this standard, the LCA is a comparative method that expresses the potential environmental impacts of individual products with respect to the life cycle [9].

The assessment consists from four phases, which are represented in ISO standards. In figure 1 are illustrated the four phases of LCA.

\section{Application of LCA at WWTPs}

\section{The goal and scope definition}

The subject of the assessment and its scope is determined in the first phase of the LCA analysis. It is necessary to clearly identify the content of the study, the meaning, the target group and the conditions under which the analysis will be valid. Characteristics of technical parameters and requirements are closely related to the determination of the study subject. Within the characteristics of the technical parameters, the functional unit, the reference flow and the system boundary are determined [4]. The goal of the analysis is the environmental impacts assessment of municipal WWTP. It serves to monitor the current state of operation with its optimization forecast.

\section{Description of the WWTP under study}

The WWTP under study is a mechanically-biological treatment plant with low entrainment activation, anaerobic sludge stabilization and with gas management. It was designed for capacity of 80,000 p.e. (person equivalent) but currently, it works just about half capacity (46 400 p.e.) because all communities are not connected to the WWTP. Nowadays, some communities that belong to the agglomeration have not built the sewer networks. In the future an increase of number the connected inhabitants and industrial activities, the increase amount of wastewater is expected.

\section{Functional unit}

The purpose of the WWTP is to remove the pollutants and reduce the emissions when the treated effluents are discharged to the aquatic ecosystem [8]. Rate of fulfillment of the functional outputs is a functional unit used to measure the comparability of LCA results [4]. According to Hospido et al. [10] the functional unit can be defined as quantity of removed pollutants, amount of treated wastewater or generated sludge. The amount of wastewater was determined as a functional LCA unit because it was based on the real measured data. 


\section{System boundaries}

System boundaries define important life cycle processes that need to be included in LCA analysis. They greatly influence the outputs of the analysis, so their correct determination is very important [8]. The boundaries of the system were defined by the potential impacts of sewage at purification levels, so the wastewater treatment system was divided into three subsystems (Fig. 2). Subsystem 1 consists of the raw waste water inflow and the mechanical treating level (pre-treatment, primary treatment). Subsystem 2 comprises the biological treating level and the discharge of the treated water into the receiving water. The subsystem 3 includes the last part of WWTP the sludge treatment. This subsystem counts the transport of the sludge and its application to the land.

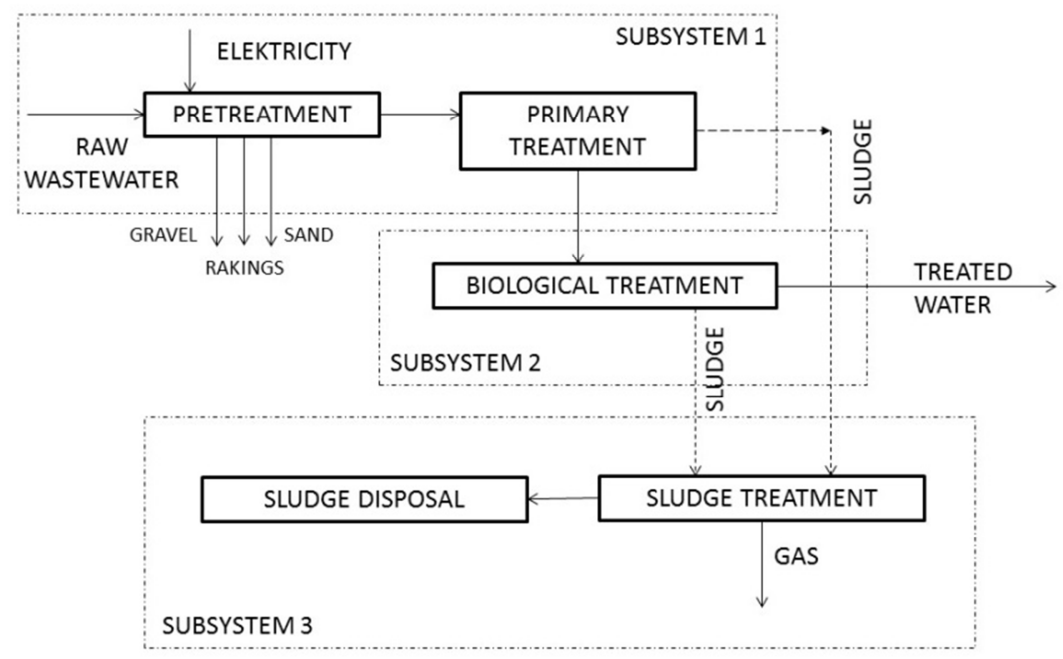

Fig. 2. Model of product system and subsystem defining

Life cycle inventory - Inventory analysis

The inventory analysis is concerned with data collection and calculation procedures that are necessary to complete the inventory [9]. It also serves to determine the number of primary flows. The primary flow represents the pollutants released into the environment during the product life cycle [4]. The inventory function is to focus on environmentally relevant information about participating processes in the product system. The output of the inventory analysis is a set of data called the ecovector. The ecovector summarizes the material flows that enter and exit the system. They are presented in inventory tables - matrices [6].

The inventory analysis is based on real measured data for the period of twelve months. All the data are presented in Table I and they showed the average measured values of the twelve months period and serve only to illustrate inventory tables. 
Extensive tables (Table II and Table III) contain of the amount of inert waste, municipal solid waste and emissions to air were used to perform the analysis.

\section{Life cycle impact assessment}

The life cycle impact assessment is the LCA phase, which aims to convert the results obtained through inventory analysis. It is the conversion of the ecovector (elementary flows) into suitably selected units of impact categories. The basic step of the evaluation is the classification of the elementary flows that are assigned to the individual impact categories. The output of this phase is the characterization profile determined by the impact category indicators [11]. The definition of impact indicators is an important step in the whole assessment process [12].

\section{Table I}

Inventory table - Basic parameters

\begin{tabular}{|l|l|l|}
\hline p. e. & 46387 & \\
WW discharge & 6675306 & $\mathrm{~m}^{3} /$ year \\
Amount of dissolved solid & 1214,9 & $\mathrm{mg} / \mathrm{l}$ \\
BOD $_{5}$ & 1018 & $\mathrm{mg} / \mathrm{l}$ \\
Average discharge & 211,1 & $\mathrm{l} / \mathrm{s}$ \\
Electricity consumption & 1516733 & $\mathrm{kWh} /$ year \\
\hline
\end{tabular}

Table II

Inventory table - Month average wastewater discharge

\begin{tabular}{|l|c|c|c|c|c|c|}
\hline Month & 1 & 2 & 3 & 4 & 5 & 6 \\
\hline WW discharge $\left(\mathrm{m}^{3}\right)$ & 563294 & 512846 & 594526 & 596892 & 578635 & 548936 \\
Month & 7 & 8 & 9 & 10 & 11 & 12 \\
WW discharge $\left(\mathrm{m}^{3}\right)$ & 547373 & 539566 & 535860 & 546675 & 529833 & 580870 \\
\hline
\end{tabular}

Table III

Inventory table - Chemical analysis of wastewater

\begin{tabular}{|c|c|c|c|}
\hline Materials & $\begin{array}{l}\text { Inflow from } \\
\text { the sewer system }\end{array}$ & $\begin{array}{l}\text { To further } \mathrm{v} \\
\text { treatment }\end{array}$ & $\begin{array}{l}\text { Emissions to the } \\
\text { Environment }\end{array}$ \\
\hline $\mathrm{pH}(-)$ & 6.94 & 7.09 & 7.26 \\
\hline $\mathrm{COD}(\mathrm{mg} / \mathrm{l})$ & 267.19 & 164.43 & 11.09 \\
\hline $\mathrm{BOD}_{5}(\mathrm{mg} / \mathrm{l})$ & 154.25 & 89.88 & 5.63 \\
\hline DS $105(\mathrm{mg} / \mathrm{l})$ & 185.09 & 86.88 & 11.14 \\
\hline $\mathrm{N}-\mathrm{NH}_{4}(\mathrm{mg} / \mathrm{l})$ & 16.47 & 13.8 & 0.66 \\
\hline $\mathrm{N}-\mathrm{NO}_{3}(\mathrm{mg} / \mathrm{l})$ & 0.29 & 0.28 & 7.67 \\
\hline $\mathrm{N}_{\text {total }}(\mathrm{mg} / \mathrm{l})$ & 22.17 & 22.31 & 10.16 \\
\hline $\mathrm{P}_{\text {total }}(\mathrm{mg} / \mathrm{l})$ & 2.46 & 1.76 & 0.44 \\
\hline 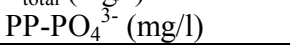 & 1.36 & 0.96 & 0.24 \\
\hline Electricity $(\mathrm{kWh} /$ year $)$ & & 1516733 & \\
\hline
\end{tabular}


At this phase collected data (from inventory analysis) are associated with environmental impact. Moreover, these impacts are analyzed and evaluated. According to ISO standards the phase comprises of mandatory and optional elements. The mandatory elements consist of the following activities: selection of impact categories, category indicators and characterization models, classification (assigning inventory to select impact categories), and characterization (modeling the inventory data within impact categories). To optional elements belong normalization, grouping, weighting and data quality analysis [13]. Normalization serves to calculating the magnitude of category indicator results relatively to reference information. Weighting is a converting indicator results across impact categories [9], [14].

In addition, the assessment used midpoint characterization model, which was based on the measurable properties of substances representing elementary streams.

\section{Software support for LCA analysis}

For easier compilation of LCA analysis some programs have been developed. They consist of two mutually interconnected functional parts. Computing software simulates product systems, performs inventory calculations, and quantifies environmental impacts. The database aggregates unit processes, material and energy flows [15].

The product system modeling begins with process insertion and their interconnection through material and energy flows. Subsequently, inventory is performed using a database that is linked to embedded processes. After inventory, the processes in the model product system are calculated using the corresponding coefficients within the range of the functional unit. The ecovector is based on the elementary flow the product system. It represents the summary of the impact category indicators.

The analysis was carried out by Open LCA, which was created in Germany by Green Delta [16]. The program allows the creation of a graphical life cycle assessment model, simulation and approximation of uncertainties. It is compatible with all databases and results export is possible in the form of XLS files and matrices.

Life cycle assessment is performed using evaluation methods that represent a set of characterization models. Elementary flow values are converted to impact category indicators using characterization models [4]. This software has been used for availability and use for assessing WWTPs. It is possible to include in the assessment different stages of WWTP operation and model situations with different loads.

Therefore, were used the International reference Life Cycle Data (ILCD 2011) system impact assessment method, that was created by the Joint Research Centre (JRC) of the European Commission. The ILCD was developed by analyzing several life cycle impact assessment methodologies to achieve a consensus on the recommended method for each environmental theme [17]. Consequently, the ILCD impact assessment method evaluates the eleven categories of impacts in the analysis i.e. acidification, climate change, resource depletion, ecotoxicity, eutrophication, human toxicity, ionizing radiation, land use, ozone layer depletion, particular matter and photochemical oxidation [15]. 


\section{Interpretation of analysis results}

The last phase of LCA presents the study results in accordance with the primary goal and scope. Results of LCA analysis is a large amount of data that needs to be sorted out and supplemented, if necessary, with more detailed data. In general, the interpretation of the analysis is based on the arrangement of the data with respect to the most important processes, analysis of sensitivity and evaluation of study uncertainties, final summary and formulation of real recommendations. Even though the quality of the effluent to the recipient meets the legislative requirements under Regulation No. 269/2010 Coll. the process of purification depends on the quality of the ecosystem.

The result of Life Cycle Impact Assessment (LCIA) is a set of reference units (Table IV). It is subsequently converted to the percentage of impact categories for a more transparent presentation.

\section{Table IV}

Impact category values

\begin{tabular}{|l|l|r|}
\hline Impact category & Reference unit & Result \\
\hline Acidification & Mole H+ eq. & 9266.0 \\
Climate change & kg CO2 eq. & 1055379.2 \\
Freshwater ecotoxicity & CTUe & 41665.0 \\
Ionizing radiation - human health & kg U235 eq. & 117829.5 \\
Land use & kg SOC & 207238.4 \\
Particulate matter/Respiratory inorganics & kg PM2.5 eq. & 592.9 \\
Photochemical ozone formation & kg C2H4 eq. & 3000.9 \\
Resource depletion & kg Sb eq. & 4246.0 \\
Terrestrial eutrophication & Mole N eq. & 10362.7 \\
\hline
\end{tabular}

Fig. 3 illustrates possible negative environmental impacts of the wastewater treatment process. The most significant negative impacts were reflected in components of global impacts $(73.2 \%)$, including climate change $(72.8 \%)$, depletion of mineral and fossil resources $(0.3 \%)$ and photochemical oxidation of ozone $(0.2 \%)$. Smaller impacts were observed for components of soil eutrophication $(0.7 \%)$ and acidification $(0.6 \%)$, which are components of regional impacts. The possible environmental impacts in the direct vicinity of the pollution source determine the magnitude of local impacts (freshwater ecotoxicity of $2.9 \%$ and ionization radiation $8.1 \%$ ).

The impacts of WWTPs on the environment can be divided into different areas. The groups of environmental influences that act on human health include human toxicity, ozone depletion, respiratory effects, photochemical oxidation and ionizing radiation. Another evaluation focused on the potential impact of the waste water treatment process on the quality of the ecosystem. The results of this analysis are presented in the following Fig. 4. The most notable impact was on climate change (79.5\%) and resource use $(15.9 \%)$. 


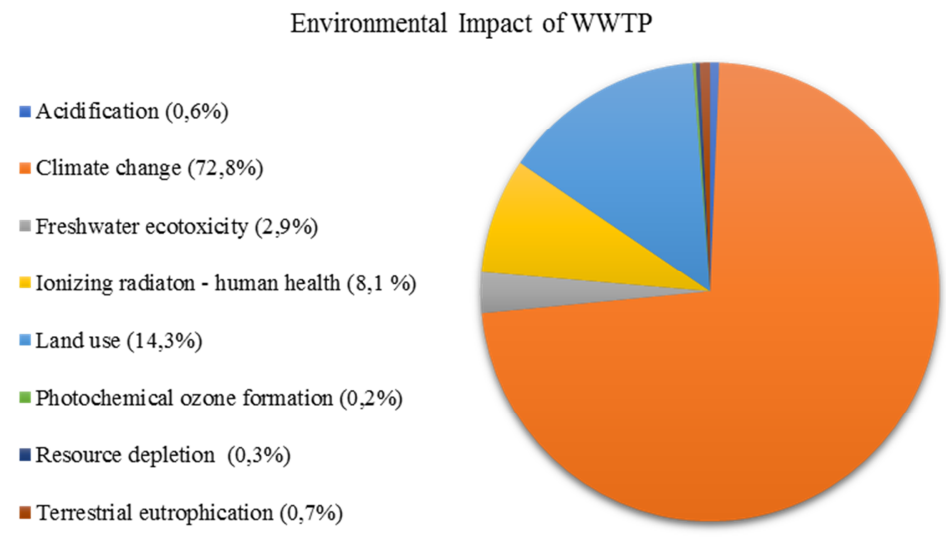

Fig. 3 Environmental impacts of WWTP

Environmental Impacts of WWTP on ecosystem quality
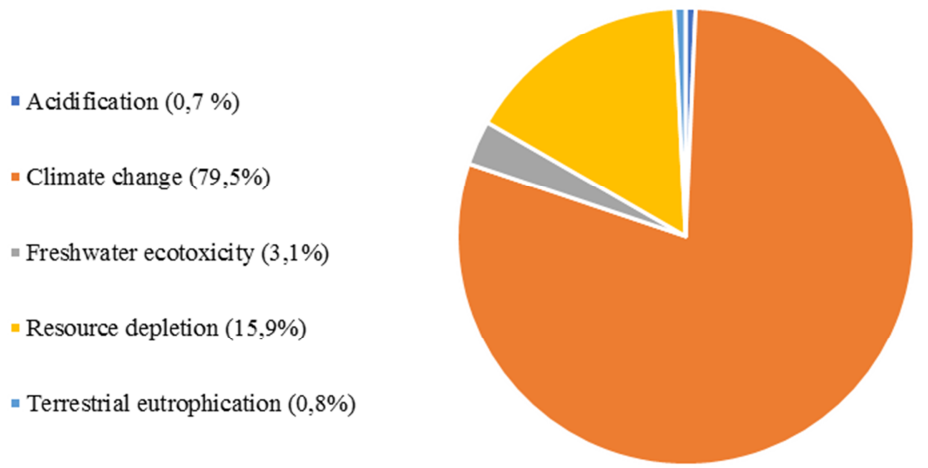

Fig. 4. Environmental impacts of WWTP on ecosystem quality

\section{Conclusion}

The aim of the paper was to evaluate the wastewater treatment plant in terms of its adverse environmental impacts by means of LCA analysis. This analysis is an optional environmental engineering instrument and assesses WWTPs in terms of its life cycle. The Open LCA software has been used to evaluate the WWTP, which is able to perform analysis using embedded databases and evaluation methods. The study results are conditional on the choice of the appropriate assessment method, the function definition, the functional unit of the system under consideration, the system boundaries and the reference units. 
During the first phase was determined as a functional unit the amount of wastewater. The system boundaries were defined by the potential impacts of wastewater purification steps. Therefore, the wastewater treatment system divided into three subsystems. The reference flow system was presented with wastewater and electricity consumed.

The function of inventory analysis is data collection and product system creation. In the next phase (LCIA) was carried out the conversion of the ecovector to suitably selected units of impact categories. Consequently, the ILCD was chosen as applicable method for this analysis. A conditioning factor for the correct assessment is also the consideration of the limit values of the indicator categories of impacts based on the applicable standards and regulations.

The analysis served to monitor the current state of WWTP operation in the order to make it more efficient.

\section{Acknowledgements}

This article was created with the support of the Ministry of Education, Science, Research and Sport of the Slovak Republic within the Research and Development Operational Programme for the project 'University Science Park of STU Bratislava', ITMS 26240220084, co-funded by the European Regional Development Fund and by the Slovak Research and Development Agency under the contract No. APVV-0372-12.

\section{References}

[1] Council Directive 91/271/EEC of 21 May 1991 concerning urban waste-water treatment.

[2] Regulation of the Slovak Government 269/2010 defining the requirements for achieving good status of waters, (in Slovak), 2010.

[3] Singovská, E., Bálintová, M. Methods of environmental risk assessment in water managemet, Pollack Periodica, Vol. 4, No. 1, 2009, pp. 105-113.

[4] Kočí V. Life cycle assessment, LCA. (in Czech), 1st Ed, Chrudim, published by Vodní zdroje Ekomonitor, 2009.

[5] Čuláková M., Šenitková I., Paulíková A. Optimalization of construction solutions for green building, Pollack Periodica, Vol. 7, No. 3, 2012, pp. 33-44.

[6] Kočí V. Essential life cycle assessment guide, (in Slovak) ETC consulting, Praha 2010.

[7] Groen, E. A., Bokkers, E. A. M., Heijungs, R., de Boer I. J. M. Methods for global sensitivity analysis in life cycle assessment, Int J Life Cycle Assess, Vol. 22, No. 7, 2017, pp. 1125-1137.

[8] Bounocore E., Mellino S., De Angelis G., Liu G., Ulgiati S. Life cycle assessment indicators of urban wastewater and sewage sludge treatment, Ecol. Indicat. 2016 https://doi.org/10.1016/j.ecolind.2016.04.047

[9] ISO 14040:2006, Environmental management, Life cycle assessment, principles and framework, International Organization for Standardization, Geneva, Swizerland, 2006.

[10] Hospido A., Moreira M.T., Fernández-Couto M., Feijoo G. Environmental performance of a municipal wastewater treatment plant, The International Journal of Life Cycle Assessment, Vol. 9, 2004, pp. 261-271.

[11] Guinèe J. B., Gorreé M., Heijungs R., Huppes G., Kleijn R., de Konig A., van Oers L., Weneger A., Suh S., Udo de Haes H. A., de Bruijn H., van Duin R., Huijbregts M. Life cycle assessment: An operational guide to the ISO standards, Leiden, 2001. 
[12] Zeleňáková M., Zvijáková L. Selection of impact indicators and their evaluation for environmnetal assessment of water construction, Pollack Periodica, Vol. 6, No. 3, 2011, pp. 83-92.

[13] Foteinis S., Monteagudo J. M., Durán A., Chatzisymeon E., Environmental sustainability of the solar photo, Fenton process for wastewater and pharmaceuticals mineralization at semiindustrial scale, Science of the Total Environment, Vol. 612, 2017, pp. 605-612.

[14] ISO 14044:2006, Environmental management, Life cycle assessment, Requirements and guidelines, International Organization for Standardization, Geneva, Swizerland, 2006.

[15] Acero A., Rodríguez C., Ciroth A. Impact assessment methods in life cycle assessment and their impact categories, LCIA methods, GreenDelta, Berlin, 2016.

[16] GreenDelta, OpenLCA, http://www.openlca.org/greendelta/, (last visited $15^{\mathrm{h}}$ November 2017).

[17] Wolf M. A., Pant R., Chomkhamsri K., Sala S., Pennington D. The international reference life cycle data system (ILCD), Handbook, 2012. 